RESEARCH ARTICLE

\title{
Experiences of Teasing and Bullying in Children Who Stutter
}

\section{Yoshikazu Kikuchi ${ }^{1 *}$, Toshiro Umezaki ${ }^{2,3}$, Motohiro Sawatsubashi ${ }^{4}$, Masahiko Taura ${ }^{1}$, Yumi Yamagu- chi $^{1}$, Daisuke Murakami ${ }^{1}$ and Takashi Nakagawa ${ }^{1}$}

\author{
${ }^{1}$ Department of Otorhinolaryngology, Graduate School of Medical Sciences, Kyushu University, Japan \\ ${ }^{2}$ Voice and Swallowing Center, Fukuoka Sanno Hospital, Japan \\ ${ }^{3}$ International University of Health and Welfare, Japan \\ ${ }^{4}$ Department of Otorhinolaryngology, Fukuoka University Chikushi Hospital, Japan
}

*Corresponding author: Yoshikazu Kikuchi, MD, PhD, Department of Otorhinolaryngology, Graduate School of Medical Sciences, Kyushu University, 3-1-1 Maidashi, Higashi-ku, Fukuoka 812-8582, Japan, Tel: +81-92-642-5668, Fax: +81-92$642-5685$

\begin{abstract}
Purpose: This study explores the experiences of children who stutter (CWS) in terms of others imitating or questioning them, or laughing at their speech patterns.

Methods: Participants were 120 CWS, aged 3-12 years, who were patients at our hospital. Each child was asked the following three questions: Has anyone asked you why you speak in that way? (questioned); has anyone imitated the way you speak? (imitated); and has anyone laughed at your speech? (laughed). We also asked if the CWS felt unhappy or happy about these responses.

Results: The total proportion of children who were questioned, imitated, and laughed at was $66.6 \%$. Most of the CWS in the study over 4-years-old felt unhappy with any of these responses to stuttering.

Conclusions: We found that even at age 4, CWS remembered non-friendly exchanges with their peers. It is important to take action against teasing and bullying through asking CWS about their experiences of being questioned, imitated, or laughed at.
\end{abstract}

\section{Keywords}

Children who stutter; Prevention; Speech disorder; Teasing; Responses to bullying

\section{Abbreviations}

CWS: Children Who Stutter

\section{Introduction}

Stuttering is a speech disorder characterized by in- voluntary repetitions or prolongations of words or syllables, or interruptions in flow of speech, known as blocks $[1,2]$. Some children may comment on another child's stuttering out of curiosity or interest. Such comments may be hurtful to a child who stutters (CWS), even when bullying was not the intent [3]. The consequences of being bullied and teased during childhood may increase social anxiety, reduce self-esteem, and lead to poorer peer relationships, among other things [4,5]. Indeed, at least $40 \%$ of adults who stutter also have a social anxiety disorder [6]. Early detection and prevention of teasing and bullying associated with stuttering is therefore needed.

Although the terms bullying and teasing are often used interchangeably, it is helpful to distinguish them [7]. In Japan, bullying refers to non-friendly exchanges between peers; this definition is based on legislation aimed at preventing bullying at elementary, junior high, and senior high schools [8]. Teasing, on the other hand, refers to an enjoyable exchange between friends, without any malicious intent. Stuttering typically arises in children aged 2-4 years, and according to parents' questionnaire, children as young as 2-years-old have been found to be aware of their own stuttering [9]. Bullying behavior can be ranked from mild to severe; imitation is classified as mild bullying [10]. In addition to being imitated, CWS are also of-

Citation: Kikuchi Y, Umezaki T, Sawatsubashi M, Taura M, Yamaguchi Y, et al. (2019) Experiences of Teasing and Bullying in Children Who Stutter. Int Arch Commun Disord 2:013. doi.org/10.23937/26434148/1710013

Accepted: December 07, 2019; Published: December 09, 2019

Copyright: (C) 2019 Kikuchi Y, et al. This is an open-access article distributed under the terms of the Creative Commons Attribution License, which permits unrestricted use, distribution, and reproduction in any medium, provided the original author and source are credited. 
Table 1: Detailed proportion of CWS who had experienced being questioned about their speech pattern, imitated, or laughed at by others.

\begin{tabular}{|c|c|c|c|c|c|c|c|c|c|c|c|}
\hline & \multirow{2}{*}{ Total } & \multicolumn{10}{|l|}{ Age } \\
\hline & & 3 & 4 & 5 & 6 & 7 & 8 & 9 & 10 & 11 & 12 \\
\hline Number of CWS & 120 & 14 & 8 & 20 & 24 & 14 & 18 & 4 & 8 & 6 & 4 \\
\hline Questioned (\%) & 44.2 & 0 & 13 & 35 & 38 & 64 & 67 & 75 & 50 & 83 & 75 \\
\hline Imitated (\%) & 30.8 & 14 & 13 & 25 & 29 & 64 & 28 & 75 & 38 & 0 & 50 \\
\hline Laughed at (\%) & 26.7 & 7 & 13 & 40 & 21 & 21 & 33 & 25 & 38 & 33 & 50 \\
\hline Total (\%) & 66.6 & 21 & 25 & 70 & 54 & 71 & 78 & 100 & 63 & 83 & 100 \\
\hline
\end{tabular}

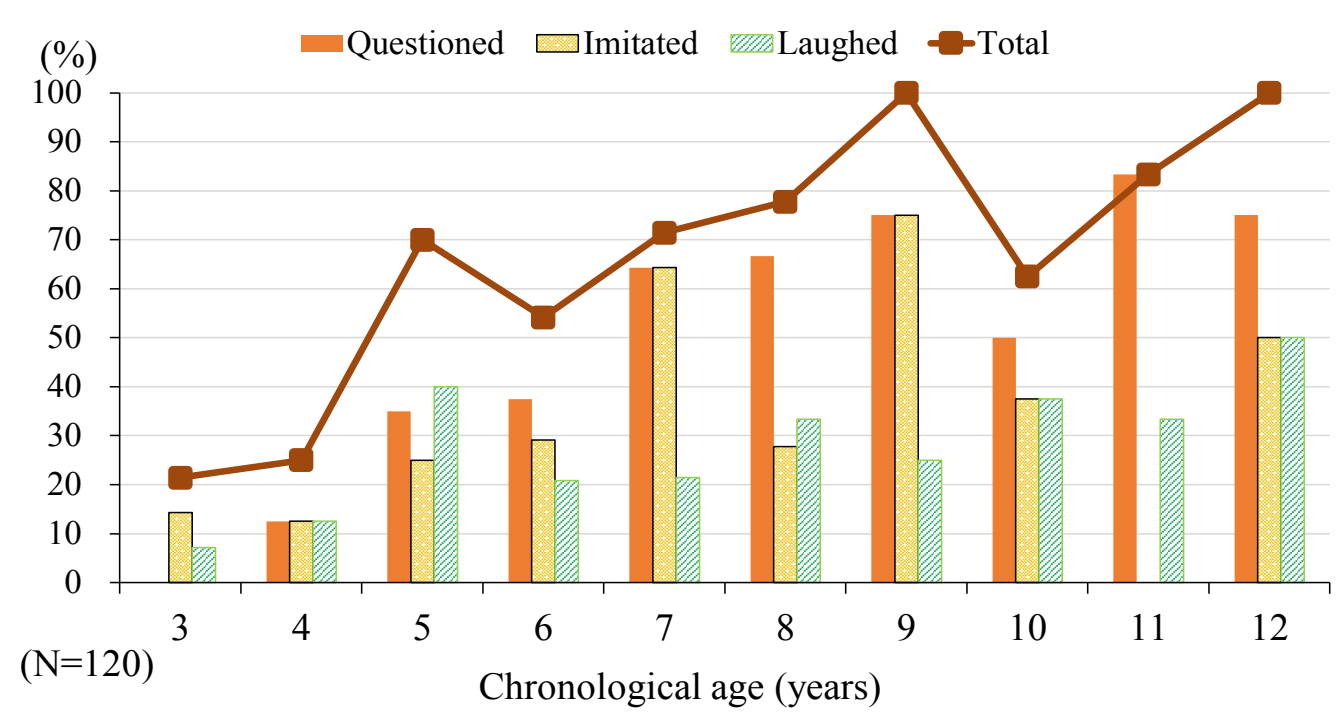

Figure 1: The proportion of CWS who had been questioned about their speech patterns, imitated, or laughed at by others.

ten questioned and laughed at. The aim of this study was to interview CWS aged 3-12 years on their experiences of being questioned, imitated, or laughed at, and to determine whether these incidents left them feeling unhappy.

\section{Methods}

Participants were 120 CWS (98 male and 22 female) between ages 3 and 12, who visited Kyushu University Hospital from 2012 to 2017 for consultations on their stuttering. The age distribution was as follows: 14 three-year-olds (12 male, 2 female); 8 four-year-olds (all male); 20 five-year-olds (14 male, 6 female); 24 six-yearolds (21 male, 3 female); 14 seven-year-olds (11 male, 3 female); 18 eight-year-olds (13 male, 5 female); 4 nineyear-olds ( 3 male, 1 female); 8 ten-year-olds ( 7 male, 1 female); 6 eleven-year-olds (all male); and 4 twelveyear-olds ( 3 male, 1 female). On first consultation, we asked each child the following three questions:

- Has anyone asked you why you speak in that way?

- Has anyone imitated the way you speak?

- Has anyone laughed at your speech?

We also asked if they felt unhappy or happy about these incidents. This study was approved by the institutional review board of Kyushu University (29-117) and was performed in accordance with the Declaration of Helsinki.

\section{Results}

The proportion of CWS who were questioned, imitated, or laughed at is depicted in Table 1 and Figure 1 . The average proportion of children who were questioned was $44.2 \%$ ( $0 \%$ at age three; $13 \%$ at age four; $35 \%$ at age five; $38 \%$ at age six; $64 \%$ at age seven; $67 \%$ at age eight; $75 \%$ at age nine; $50 \%$ at age ten; $83 \%$ at age eleven; and $75 \%$ at age twelve), those who were imitated was $30.8 \%$ (14\% at age three; $13 \%$ at age four; $25 \%$ at age five; $29 \%$ at age six; $64 \%$ at age seven; $28 \%$ at age eight; $75 \%$ at age nine; $38 \%$ at age ten; $0 \%$ at age eleven; and $50 \%$ at age twelve), and ones who were laughed at was $26.7 \%$ ( $7 \%$ at age three; $13 \%$ at age four; $40 \%$ at age five; $21 \%$ at age six; $21 \%$ at age seven; $33 \%$ at age eight; $25 \%$ at age nine; $38 \%$ at age ten; $33 \%$ at age eleven; and $50 \%$ at age twelve). The total proportion of children who were questioned, imitated, and laughed at was $66.6 \%$ (21\% at age three; $25 \%$ at age four; $70 \%$ at age five; $54 \%$ at age six; $71 \%$ at age seven; $78 \%$ at age eight; $100 \%$ at age nine; $63 \%$ at age ten; $83 \%$ at age eleven; and $100 \%$ at age twelve). There were no gender differences. 


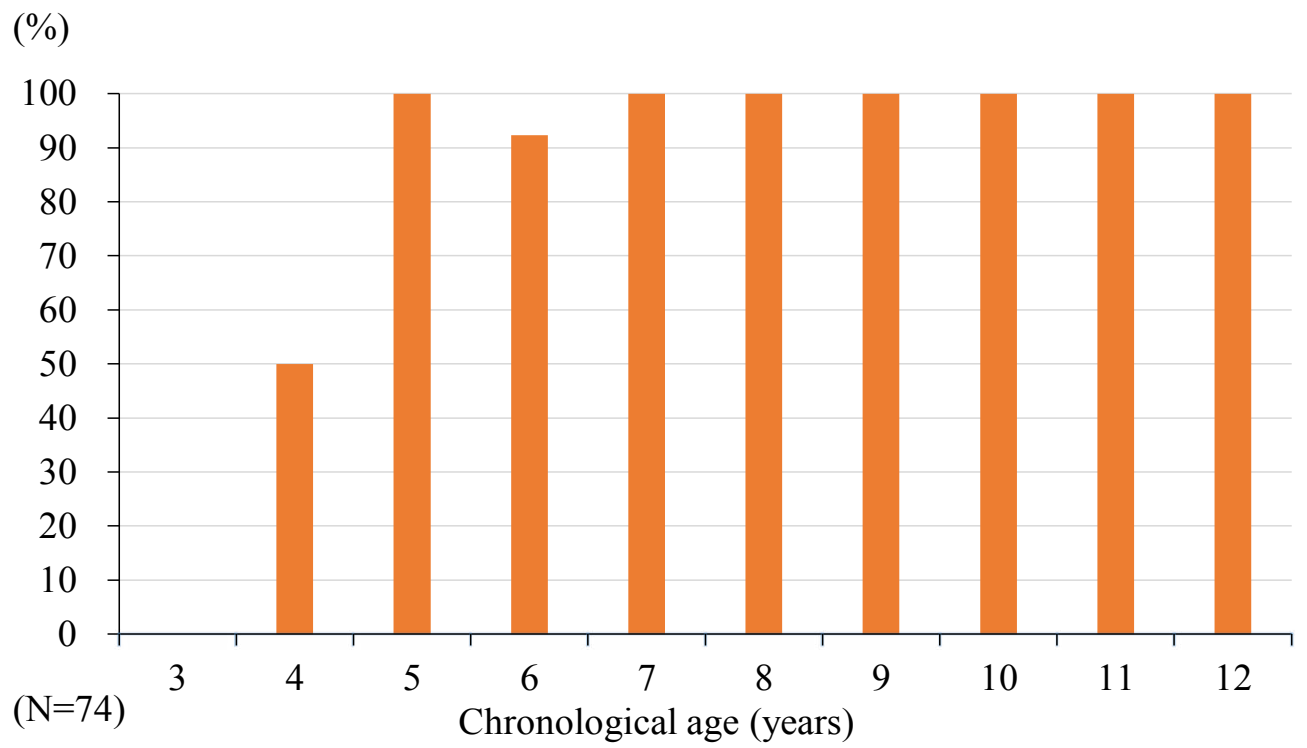

Figure 2: The proportion of CWS who were "unhappy" with being questioned, imitated, or laughed at, according to age.

The percentage of CWS who were unhappy with being questioned, imitated, or laughed at is depicted in Figure 2. The distribution of CWS who were unhappy, was $0 \%$ at age three; $50 \%$ at age four; $100 \%$ at age five; $92.3 \%$ at age six; $100 \%$ at age seven; $100 \%$ at age eight; $100 \%$ at age nine; $100 \%$ at age ten; $100 \%$ at age eleven; and $100 \%$ at age twelve.

\section{Discussion}

This is the study to ask CWS as young as age three and over about their attitudes to being questioned, imitated, or laughed at regarding their stuttering. The proportion of CWS who were questioned exceeded those who were imitated or laughed at. Ezrati-Vinacour et al [11] reported that preschool children with normal fluency are fully aware of stuttering-like disfluencies at age five. Half of four-year-old CWS did not feel unhappy about being questioned, imitated, or laughed at. We recommend that physicians and speech language pathologists ask CWS over age four whether they were questioned, imitated, or laughed at, to detect bullying associated with stuttering.

We did not find three-year-olds who felt unhappy with being questioned, imitated, or laughed at. Boey et al [9] found that children are aware of their own stuttering from as early as two years old, based on parental-reported unambiguous verbal and non-verbal reactions in response to stuttering. However, the study by Boey et al [9] explored difficulties of CWS from the perspective of parents, while our study examined children's memories of experiences with their peers. The difference in findings may be related to children's ability to process experiences and emotions, which increases with age.

There are some studies on bullying detection. Langevin et al [10], with the help of 19 items of The Teasing/Bullying Questionnaire for Children Who Stutter (TBQ-CS), reported that nearly $60 \%$ of children aged
7-15, who stuttered frequently, experienced bullying behaviors. Blood and Blood [4] examined adults who stuttered, using 46 items of the Retrospective Bullying Questionnaire (RBQ); their findings showed that $30.6 \%$ of participants were bullied in primary school, $27.8 \%$ in secondary school, and $11.1 \%$ in university. Furthermore, Hugh-Jones and Smith [12] reported that $75 \%$ of adults who stuttered believed that the bullying they experienced in school had affected their academic performance. There were many strategies of addressing bullying $[3,13]$ and Yaruss et al [14] summarized six key steps to prevent and minimize bullying: (1) Educating children about stuttering; (2) Educating children about bullying; (3) Helping children change the way they think and feel about their stuttering through desensitization, cognitive restructuring, and acceptance activities; (4) Helping children learn to use appropriately assertive responses that decrease the likelihood of bullying; (5) Educating peers and bystanders about stuttering and bullying so that they are more likely to respond in helpful ways; and (6) Educating parents, teachers, and administrators about how they can create an environment where it is not okay to bully, but it is okay to stutter.

The limitation of this study was the lack of data on stuttering severity of the participants, and it is likely that more severe stuttering may lead to an increase in bullying severity. However, even CWS who had a minimal stutter in our examination were bullied by their classmates; stuttering severity may not be the only factor determining the severity of bullying.

\section{Key Messages}

- A large proportion of children who stutter are questioned, imitated, and laughed at.

- Children who stutter are bullied from as young as four-years-old. 
- Bullying impacts people who stutter into adulthood.

- Psychological effects of bullying should be addressed by holistic treatment.

\section{Acknowledgments}

This work was supported by Grant-in-Aid for Young Scientists (B) 17K16922 and Japan Agency for Medical Research and Development (AMED) 17dk0310066h0202 and 19dk0310102j0001. We would like to thank Editage (www.editage.jp) for English language editing.

\section{Disclosure Statement}

The authors have no conflicts of interest to disclose.

\section{References}

1. Kikuchi Y, Umezaki T, Adachi K, Sawatsubashi M, Yamaguchi $Y$, et al. (2018) Evaluation of vocal fold motion during blocks in adults who stutter. Int Arch Commun Disord 1: 1-6.

2. Kikuchi $Y$, Umezaki T, Uehara T, Yamaguchi $H$, Yamashita $\mathrm{K}$, et al. (2018) A case of multiple system atrophy-parkinsonian type with stuttering-and palilalia-like dysfluencies and putaminal atrophy. J Fluency Disord 57: 51-58.

3. Murphy WP, Yaruss JS, Quesal RW (2007) Enhancing treatment for school-age children who stutter: II. Reducing bullying through role-playing and self-disclosure. J Fluency Disord 32: 139-162.

4. Blood GW, Blood IM (2016) Long-term consequences of childhood bullying in adults who stutter: Social anxiety, fear of negative evaluation, self-esteem, and satisfaction with life. J Fluency Disord 50: 72-84.
5. Hymel S, Swearer SM (2015) Four decades of research on school bullying: An introduction. American Psychologist 70: 293.

6. Blumgart E, Tran Y, Craig A (2010) Social anxiety disorder in adults who stutter. Depress Anxiety 27: 687-692.

7. Coloroso B (2003) The bully, the bullied, and the bystander. New York, NY: HarperCollins Publisher, Inc.

8. Horii M (2015) The Meaning of Legislation and Problem of "Act to Accelerate Countermeasures against Bullying": Formative Process of Law and Policy on Bullying. Kokushikan Journal of the Humanities 47: 1-18.

9. Boey RA, Van de Heyning PH, Wuyts FL, Heylen L, Stoop $R$, et al. (2009) Awareness and reactions of young stuttering children aged 2-7 years old towards their speech disfluency. J Commun Disord 42: 334-346.

10. Langevin M, Bortnick K, Hammer T, Wiebe E (1998) Teasing/bullying experienced by children who stutter: Toward development of a questionnaire. Contemporary Issues in Communication Science and Disorders 25: 12-24.

11. Ezrati-Vinacour R, PlatzkymR, Yairi E (2001) The young child's awareness of stuttering-like disfluency. J Speech Lang Hear Res 44: 368-380.

12. Hugh-Jones S, Smith PK (1999) Self-reports of short- and long-term effects of bullying on children who stammer. $\mathrm{Br} J$ Educ Psychol 69: 141-158.

13. Blood GW, Boyle MP, Blood IM, Nalesnik GR (2010) Bullying in children who stutter: Speech-language pathologists' perceptions and intervention strategies. J Fluency Disord 35: 92-109.

14. Yaruss JS, Reeves N, Herring C (2018) How speech-language pathologists can minimize bullying of children who stutter. Semin Speech Lang 39: 342-355. 